\title{
Illness perceptions of Turkish Cypriot patients receiving haemodialysis: A qualitative study
}

\section{Keskindag et al.}

\author{
Buse Keskindag ${ }^{1,2}$, Ken Farrington ${ }^{1}$, Duriye Deren Oygar ${ }^{3}$, Biran Mertan ${ }^{2}$, Abigail Hucker ${ }^{1}$, \\ Shivani Sharma ${ }^{1}$
}

1. School of Life and Medical Sciences, University of Hertfordshire, UK

2. Psychology Department, Bahçeşehir Cyprus University, North Cyprus.

3. Burhan Nalbantoglu State Hospital in Nicosia, North Cyprus.

Corresponding Author:

Buse Keskindag,

School of Life and Medical Sciences,

University of Hertfordshire,

Hatfield, UK

b.keskindag@herts.ac.uk

\section{Author Contributions}

$\mathrm{BK}, \mathrm{KF}$ and SS conceptualised the study. DDO acted as the in country principal investigator and BM acted as the in country researcher. BK collected and analysed the data. AH was involved with quality assurance and refining the analysis. All authors contributed to interpreting findings. BK and SS drafted the manuscript, which was edited and approved by all.

\section{Conflict of Interest:}

No conflict of interest has been declared by the authors.

\section{Acknowledgements}

We would like to thank all patients who contributed to the study for sharing their experiences and time. Also, we would like to thank Zihniye Okray for helpful comments in the early stages of planning the research.

\section{Bio data}

Buse Keskindag is a PhD student within the School of Life and Medical Sciences at the University of Hertfordshire, UK. She has a master's degree in Health Psychology. Her research focuses on the relationship between illness perceptions and clinical outcomes in patients receiving dialysis. 


\begin{abstract}
Background: Illness perceptions refer to cognitive appraisals that help patients understand and make sense of their condition. Although their importance in health behaviour and outcomes has been evidenced, less is known about cultural influences on mental representations of kidney failure amongst patients receiving haemodialysis in different settings.
\end{abstract}

Objective: To explore the illness perceptions of Turkish patients receiving haemodialysis in North Cyprus (Turkish Cypriots).

Design: A qualitative study involving individual semi-structured interviews.

Participants: Fourteen patients receiving haemodialysis, recruited from three state hospitals in North Cyprus.

Approach: All interviews were conducted in Turkish, audio-recorded, and transcribed verbatim. They were analysed inductively in the original language using reflexive thematic analysis. Once the analysis was completed, it was translated into English. Quality assurance was integral to the research process to retain semantic equivalence.

Findings: Three themes were developed. 'Illness appraisal' highlighted a lack of factual knowledge about kidney failure and how this related to attempts at sense-making, whilst retaining hope for the future. 'Life changing effects' centred around the negative consequences of haemodialysis across multiple domains (e.g., emotional and physical). 'Active coping strategies' focused on mechanisms that patients adopt to manage the burden of haemodialysis, particularly approaches that are culturally rooted.

Conclusion: There is a need for better communication to address the lack of individual patient knowledge about kidney failure. Haemodialysis is described as a burdensome treatment though existing coping mechanisms suggest that psycho-spiritual interventions may be advantageous to aid adjustment for Turkish Cypriots receiving haemodialysis. 
Keywords: Kidney failure; Haemodialysis; Patient; Qualitative research

\section{Illness perceptions of Turkish Cypriot patients receiving haemodialysis:}

\section{A qualitative study}

\section{Introduction}

Haemodialysis (HD) is a life-saving intervention for patients requiring kidney replacement therapy (KRT) for the treatment of kidney failure. However, it is burdensome (Jones et al. 2018; Tong et al. 2009) and there is increasing recognition that individuals vary in how they cope. This has spurred research into factors that help explain differential responses. The Common Sense Model (CSM) of Self-Regulation (Leventhal et al. 2003) is a well-known theoretical framework that has been used to describe how patients manage their condition (Hagger et al. 2017; Leventhal et al. 2016). According to the model, following the onset of illness, patients develop a set of organised beliefs, referred to as illness perceptions, that shape their attempts at coping. A body of research has delineated the role of illness perceptions as psychological associates of important outcomes, making them focal in efforts to support patient adjustment.

\section{Literature Review}

Illness perceptions are structured into five clusters and include: Identity, representing the meaning of labelling oneself with an illness and the associated symptoms; Causality, that is the attribution of causal factors; Timeline, referring to beliefs and ideas about the duration of the condition; Control/ Cure refers to whether patients believe that their condition is controllable or curable; and Consequences refer to beliefs about the impact of the condition (Leventhal et al. 2003). Patients develop individual cognitions related to their condition 
(Petrie \& Weinman 2006) and equally, illness perceptions may change over-time, leading to both inter and intra individual variation (Bonsaksen et al. 2015). Illness perceptions can be measured using either the revised Illness Perception Questionnaire (IPQ-R) (Moss-Morris et al. 2002) or a shorter version- the Brief Illness Perception Questionnaire (IPQ-B) (Broadbent et al. 2006). This has given rise to numerous studies that quantify illness experiences and relate them to a broad range of psychological and clinical outcomes in patients receiving HD including quality of life (Nabolsi et al. 2015; Patel et al. 2002), diet adherence (Kim \& Evangelista 2010; Seyyedrasooli et al. 2013), depression (Chilcot 2012; Peterson et al. 1991), and mortality (Parfeni et al. 2013). Qualitative exploration of how patients construct meaning is lacking (Chilcot 2012), though more is known specifically about the experience of HD (Rees et al. 2018; Tong et al. 2009). It is also fair to say that the current state of knowledge on the role of illness perceptions in self-regulation draws heavily on studies of white European/American patient groups. Under-representing patients from different racial or ethnic groups in research may miss important elements of illness experience that are shaped by culture (Sharma et al. 2019).

Turkey (Stel et al. 2011) and Cyprus (Connor et al. 2013) have high incidence rates of kidney failure. However, Cyprus is in a distinct cultural context. Historically, it has been governed by both Greek and Ottoman Turks. Consequently, the population mix is different from that of either Turkey or Greece (Connor et al. 2013; Kizilyürek \& Gautier-Kizilyürek 2004). The majority of Northern Cypriot patients with kidney failure (91.1\%) start KRT by in-centre HD treatment (Connor et al. 2013), making it important to understand adjustment to HD as a specific KRT modality. There are no studies on illness perceptions amongst TurkishCypriot patients receiving HD. To address this, we used a qualitative study design to explore patients' beliefs about and understanding of kidney failure. A qualitative design was selected 
as this approach is useful to describe previously unidentified contexts (Tong et al. 2014) and offers a mechanism for understanding depth of experience (Vandermause et al. 2017).

\section{Method}

The findings are presented according to the Consolidated criteria for reporting qualitative health research (COREQ) (Tong et al. 2007).

\section{Patient Recruitment}

There are three state hospitals providing HD in North Cyprus. Patients who met study inclusion criteria were identified by nurses who work at Renal Services across these sites. Inclusion criteria were aged 18 years and above, receiving HD treatment for at least 6 months, and verbal fluency in the Turkish language. Patients who had received mental health intervention within the last year, those who had specific intellectual difficulties, and those with life expectancy of less than one year (i.e., patients who receive end of life care) were excluded. A purposive sample (Patton 2015) of 19 patients who met study inclusion criteria were invited to participate by providing them with both a face-to-face as well as written explanation about the study (in Turkish). We aimed to capture diversity in the number of years receiving HD, self-identified gender, alongside co-morbidities whilst attending to clinical knowledge on patients who would be able to communicate their experiences well. Fourteen patients accepted where 5 declined. The majority of those $(n=3)$ who declined to participate said that they had a busy schedule and did not have spare time for the study. All patients were Turkish Cypriots and identified as Muslims.

\section{Study Design and Data Collection}


This was a qualitative study involving individual, face-to-face, semi-structured interviews. An interview topic guide was designed to broadly cover patient responses to life on HD but without imposing findings derived from other patient populations. The topic guide included 10 open-ended questions focusing on illness experiences such as 'Do you know what the cause of your kidney disease is? How did you gain information about this?' Prompts were used where appropriate to encourage patients to elaborate. The questions were first developed in English to cover the domains of illness perceptions, and forward translated into Turkish with a focus on semantic meaning. At this stage, reference was made to the Turkish version of the B-IPQ (Oflaz et al. 2014) and the Multimorbidity Illness Perceptions Scale (Gibbons et al., 2013) so as to compare linguistic expression of the same/similar concepts.

Most $(n=12)$ patients preferred to complete the study at their home while two completed the study before their HD session in a private room at the Renal Service. In one interview, the partner of a patient was present. All interviews were audio recorded and lasted between 35 minutes to an hour. The interviews were conducted by the first author (BK) who is a Turkish Cypriot, and actively researching patient adjustment to HD specifically.

\section{Data Analysis}

Interviews were transcribed verbatim and analysis progressed in Turkish. Transcripts were inductively analysed using reflexive thematic analysis (Braun \& Clarke 2006; 2013). Reflexive thematic analysis is well suited to questions related to the construction of meaning and often clusters with a critical realist approach where the researchers are attempting to represents a reality that is evident within the data (Braun \& Clarke 2013). The entire dataset was read multiple times to become familiar with it. Interesting elements of verbatim text were coded, with the codes and all relevant data extracts combined. Codes were then revisited and collapsed into themes with the use of both semantic and latent labelling. After developing 
themes, all codes were re-checked for the entire dataset to ensure that they represented patients' experiences and ensuring a good fit with the developed themes. The analysis was undertaken by BK, who is a native speaker of Turkish.

There is a debate about whether translated data still hold the same meaning as when in the origin language narrative (Regmi et al. 2010). To avoid issues such as a loss in meaning, it is recommend that researchers stay in the original language as much as possible (Temple \& Young 2004; van Nes et al. 2010). For this reason, the analysis was completed in Turkish, after which all interviews were forward translated by BK into English, alongside the themes and their associated subthemes. All translations were independently checked for semantic equivalence and any discrepancies resolved through discussion. Once translated into English, AH checked the applicability of the thematic framework by revisiting $20 \%$ of all interview data. Discussion between $\mathrm{AH}$ and BK further refined the analysis. This related exclusively to the ordering of subthemes as opposed to changing the interpretation of findings. The research team, which includes a mix of both native English and Turkish speakers, all agreed the themes and subthemes as a meaningful representation of patient experiences.

\section{Ethical Considerations}

Ethical approval was granted by both the Burhan Nalbantoglu State Hospital, Department of Inpatient Treatment, Ministry of Health in Turkish Republic of Northern Cyprus (YTK 1. 01629-19-E. 1114) and the Health, Science, Engineering and Technology Ethics Committee with Delegated Authority at the University of Hertfordshire (LMS/PGR/UH/03879). 


\section{Findings}

Table 1 describes the demographic and clinical characteristics of the patients who took part in the study. Eight males and 6 females contributed. HD vintage ranged from 6 months to 12 years, with two patients having had experience of a different modality of KRT also (peritoneal dialysis). Patients ranged in age from 48 to 82 years, and all had at least one additional co-occurring condition.

Table 2 summarises the thematic analysis. Three themes were identified: illness appraisal; life changing effects; and active coping strategies. Each theme and its associated subthemes are summarised below with reference to the illness perceptions framework.

\section{Illness appraisal}

This theme relates to how patients interpreted their condition. It included 3 subthemes focusing on causal beliefs (causality), sense-making (identity), and expectations related to the future (cure).

\subsection{Causal beliefs}

The majority of patients did not have a clear idea about the cause of their illness and did not indicate a specific cause:

'There is no a specific reason, it [kidney failure] can happen to anyone...there is no cause' (P9, male, 76).

However, some patients held beliefs about causality that appeared to be related to the experience of previous health issues:

'I had flu and cough, I stayed 5 days in the hospital, I didn't have a fever, the antibiotics that they gave me damaged the kidney so my creatinine value reached 6.33 
suddenly... the antibiotics used for the cough deteriorated my kidney' (P5, female, 77).

A minority assumed that hypertension was the cause of their illness:

'I don't know why... I was at work, suddenly my tension [referring to hypertension] increased... it was a kidney problem... I stayed at the hospital for 3 months and I am dialysis patient since then' (P6, female, 61).

Overall, there was no consensus in relation to attributing specific causal mechanisms to kidney failure.

\subsection{Sense-making}

Patients believed that they did not receive a sufficient explanation related to their condition during the diagnosis process:

'I would like to get more information... it was not sufficient... they [health care professionals] should inform patients regularly' (P6, female, 61).

Most patients reported that their kidneys deteriorated quickly although they did not have symptoms earlier. That is, the process of getting the diagnosis was short with no specific symptoms identified with kidney failure to support a coherent sense of illness. With the severity of the condition necessitating prompt HD, most held a critical attitude towards local health care, and attempted to get confirmation about the diagnosis and treatment. Therefore, they visited health care centres in Turkey and/or South Nicosia (Republic of Cyprus) in addition to the local hospitals:

'I also visited another doctor in South (Nicosia) but he said there is nothing to do... and I have started to dialysis treatment' (P2, female, 64). 


\subsection{Expectations for the future}

Despite limited knowledge of kidney failure, patients were aware of and hopeful for the opportunity of receiving a kidney transplant. However, those who were eligible did not accept living donation from their own family as an option. They had a negative opinion about getting a kidney from their partners or children since patients were afraid of harming the well-being of the relative by making him/her 'deficient'. However, deceased donation was at the forefront for most:

'My son said to me that he will give his kidney to me, I said to him that I do not accept! I have lived this much anyway. I cannot make my son half also... now my daughter has started to say that she will give me a kidney when she is 18 years old... never! Even if I know that I will die I will not accept a kidney from my children ... but I am on the list [for transplantation] at the hospital' (P14, female, 48).

Expectations for the future were also closely related to how patients were physically and mentally adjusting to receiving HD. It was notable that those who reported less negative impact in these domains were more readily able to hold positive expectations of the future outlook of illness:

'We expect beautiful days so that we will have beautiful future... some friends [other patients] wish to die to get rid of this disease... this is a wrong idea I think' (P6, female, 61).

On the other hand, those who negatively evaluated their illness were quite pessimistic about the progression of their illness:

'I believe there are very bad days waiting for me in future, very bad days... because I see those who are in worse condition now' (P1, male, 76). 


\section{Life changing effects}

The majority of patients explicitly emphasised HD negatively affecting their life experience. Four subthemes represent different clusters of consequences including physical, emotional and cognitive, and social which together fed into 'normalising' the experience of receiving HD.

\subsection{Physical}

Most patients experienced several physical changes after they started to receive HD. Persistent exhaustion and fatigue was a common complaint. It was considered as a significant obstacle to maintaining social activities and to be an active person. Patients agreed that exhaustion changed their routine hence they experienced themselves as someone different who was unable to do things in the same way as in the past. For instance, fatigue associated with otherwise day-to-day activity:

'You cannot do your things properly... you feel tired when you feel like walking somewhere' (P7, female, 48).

Notably, male patients were forthcoming in disclosing how such physical consequences had impacted their sexual life. This was important to them where no female patients made such reference:

'You feel that sexuality decreases, you do not have strength' (P1, male, 76).

\subsection{Emotional and cognitive}

Patients felt as though they were not the person they used to be. They expressed feeling less than 'normal', describing this as 'half' of themselves after they started to receive HD. Consistent reference within and between interviews to 'feeling half' and 'feeling of not being a normal person anymore' were indicative of negative self-concept. Male patients related 
these feelings to their negatively impacted sexual life, where females linked being 'halfperson' with an inability to do housework and disengagement with social activities. This evidences the overlapping nature of physical and emotional/cognitive symptoms:

'I have changed... I am not same anymore... not even a half, I have become a quarter of the quarter' (P8, male, 75).

Anger emerged as one of the most obvious emotional changes that patients experienced, particularly during the early stages of the HD treatment, and in response to symptoms experienced and other triggers in the environment:

'Especially at the beginning... you are in pain... suddenly you feel angry' (P5, male, 77).

'It [HD] changes the person a lot... if somebody says something, you immediately start to shout' (P14, female, 48).

\subsection{Social restriction}

Patients felt that they were socially restricted since they had to attend dialysis sessions 3 times a week. The time they had to spend during dialysis sessions limited their engagement with their social life. Although most patients were retired, they felt they had limited time to arrange activities that they were otherwise interested in:

'We [referring to wife] are retired, we were thinking that we would go for trips when we were retired, but how do I go for trips when I have dialysis 3 times in a week?

Once we went to Paris, but we had to return after two days since I had dialysis on the next day. I would like to go on trips, but I cannot' (P1, male, 76).

\subsection{Normalising HD}


Despite the physical and emotional consequences of receiving HD, patients recognised that they needed to normalise this experience. This process itself can be seen as a life changing effect of kidney failure where ones sense of self needs to become that of a 'patient' receiving HD. For instance, the patients mentioned how acceptance of the treatment in its entirety is critical to survival. They recognised possible consequences in not accepting to receive dialysis regularly:

'Whoever did not accept this disease died... there was a man who was on the next bed at the hospital (for dialysis) ... he was telling me: 'I am not like you'. He didn't want to receive dialysis, he died later' (P9, male, 76).

Patients knew they had to attend dialysis sessions to maintain their lives hence, they felt like they were forced to adjust to the HD. Their motivation for the adjustment was to decrease the possibility of negative illness experiences such as further deteriorating the kidneys, and accordingly extended dialysis sessions:

'I go to dialysis because I have to... but I see some patients do not want to go, but dialysis cannot be skipped, otherwise, you might end up spending 5 hours instead of 4 hours in the dialysis session... kidney may worsen, that is why, you should not skip, yes it is difficult but there is no other cure' (P12, male, 82).

At the same time, comparison to other patients also acted to normalise both some positive and negative elements of life on HD. Some patients appreciated their own condition when they witnessed others in a worse position:

'I see other patients, they are feeble... I try to feel better as I am not like them' (P2, female, 64).

On the other hand, some experiences reminded patients of the possible negative consequences associated with HD. For instance, one patient who lost a friend (another patient) who received dialysis said: 
'When I didn't see my friend (another patient) who normally lie down next to me (at the hospital for during the dialysis session), I asked what happened to him, they (health care professionals) told me that he passed away... those in good health status, we chat normally but they die the next day... so we know that fate is waiting for us' (P5, male, 77).

Whilst receiving HD is associated with a number of negative consequences in terms of physical, emotional/cognitive and social experiences, patients also need to accept some normalising of $\mathrm{HD}$ as an added effect of living with kidney failure.

\section{Active coping strategies}

Patients developed various coping strategies to manage the difficulties of kidney failure and burden of HD. These strategies were summarised in 3 clusters: religious/spiritual attitudes, social support and cognitive reframing. All relate to beliefs about cure/control.

\subsection{Religious/spiritual attitudes}

Attitudes related to fate were recurrent and represented the idea of 'it is meant to happen'. Patients highlighted the role of fate by indicating how they had limited control over their illness because of fate:

'What I can do... it is not something that is in my hand, it was in my fate' (P7, female, 48).

For some patients, belief in fate facilitated the acceptance of the illness and the treatment:

'It [illness] is something that comes from God, it is not something that comes from the people [servants] ... you have to accept it in order to have a normal life, there is no other option' (P9, male, 76). 
Patients explicitly expressed their gratitude towards God for not being in a worse condition. Thanking/appreciating for the current status was perceived as a way of avoiding negative thoughts about the illness:

'You should say thank God... otherwise, it gets worse if you keep thinking about it' (P4, male, 81).

Also, they reported praying not to be in a worse condition in future:

'I always pray God that I do not want to have to become bedridden, I couldn't bear with it' (P14, female, 48).

\subsection{Social support}

All patients received social support from their families. This encouraged them to cope with their illness and the burden of HD. Many mentioned their families helping them in daily life such as taking them to the hospital for dialysis or regular appointments, making their food and sharing the housework:

'My husband also changed with me, for instance, he was making a problem related to some things earlier, he now doesn't do, now he sees me that I am sick, he doesn't go outside much, he is often at home... for instance, if I am not able to make food, he doesn't have any problem with it... he even helps to wash the dishes' (P2, female, 64).

\subsection{Cognitive reframing}

Some patients shared an attempt to have a positive attitude about their condition. They used several ways to develop a positive attitude such as focusing on current capabilities:

'I can drive my car... I haven't had any problem yet... I do the errands by myself'

(P11, male, 76). 
Others tried to displace the thought of having an illness. They attempted to do this by avoiding the reality that they were diagnosed with kidney failure and required HD:

'I am trying to fool myself as if this [dialysis] is like my job that I should go to. I tried to see it as a job. I do not like hospital food, but I consider the water they (hospital) provide as my salary (with a laugh). So, I am being pollyannaish!' (P1, male, 76). Some patients also believed that admitting to being sick was like a self-fulfilling prophecy and they did not want to adopt a 'patient identity':

'You shouldn't mind at all, you shouldn't think about it... If you say that you are sick and if you are obsessed with it, you will end up sick' (P4, male, 81).

\section{Discussion}

This is the first qualitative study on illness perceptions in Turkish Cypriot patients receiving HD. The theme of 'illness appraisal' highlighted that patients did not hold well defined beliefs about the cause of kidney failure. This is compounded by the perceived inadequacy of information offered at the time of diagnosis. There was also a lack of illness identify in that patients could not attribute distinct clusters of symptoms as kidney failure. Findings concur with studies on illness beliefs of patients in other settings (Kazley et al. 2015; Ng et al. 2016) and suggest that knowledge is limited despite some patients receiving HD for up to 8 years. Understanding why patients had not developed more defined illness beliefs overtime will be important to address. Interestingly, knowledge was not a barrier to optimism for the future. Most patients appraised their illness as one that would change as gleaned through hope for a transplant alongside expectation of 'better days' to come. Notably, the patients in this study were more hopeful for a deceased donor transplant, with negative concepts about accepting a living donation. Research with Muslims residing in other regions has shown that family 
willingness is generally high to donate a kidney (Sadagah et al. 2020). Our findings suggest that campaigns targeting patient acceptance of living donation may be needed.

The theme of 'life changing effects' centred on consequences associated with HD, which patients somehow normalised. Previous research suggests that patients eventually accept the inevitable requirement of HD for their lives (Wu et al. 2015) despite physical and psychological difficulties (Nabolsi et al. 2015; Shirazian et al. 2017). Fatigue was a particular concern, with recent research also suggesting that at least $50 \%$ of patients are significantly impacted (Picariello et al. 2019). In parallel with prior qualitative studies (Jones et al. 2018; Tong et al. 2009), many patients reported that they were no longer able to travel and go for holidays because of the fatigue as well as the restriction of needing dialysis itself. It was not surprising that only male patients were forthcoming in how altered physical capacity impacted their sex life. For women from some Muslim cultures, sex is both a sensitive topic and one that cultural norms may advance as an obligation to a spouse (Azar et al. 2016). The extent to which our findings therefore reflect gendered differences versus willingness to disclose is unclear.

Emotional distress was common as another 'life changing effect'. Patients receiving HD tend to show depressive (Bujang et al. 2015; Chilcot et al. 2018; Cukor et al. 2006; Shirazian et al. 2017) and anxious symptoms ( $\mathrm{Ng}$ et al. 2015) regardless of cultural differences (Gerogianni et al. 2019; Loosman et al. 2015). Many stressors including time spent on dialysis, restrictions of day-to-day life, and other aspects of treatment regimens are all likely to affect the emotional status (Kittiskulnam et al. 2017). Distress may also be a response to physical and emotional burden of the treatment (Jones et al. 2018). Similar to the findings of Tong et al. (2009), the patients in this study reported feeling less than normal which may be considered as a negative self-concept. As physical symptoms are continuously 
experienced from HD, it can result in inconsistency between personal and patient identity with patients struggling to maintain a normal status (Rees et al. 2018) and their own selfesteem when prognosis is uncertain (Tong et al. 2009). This may explain the patients' negative view of themselves and feeling as though something has been lost in the 'halving' of their identity/ capacity. Adjusting to this new sense of self is also an essential consequence of living with kidney failure.

'Active coping strategies' defined the ways in which patients attempted to manage the demands of illness and the burden of HD. Religious/spiritual coping was evident. The belief that their condition was controlled externally, by something bigger, helped patients accept their illness. Acceptance that life events are determined by fate does not prevent working for more positive outcomes (Yeoh et al. 2017). Religious faith has been indicated as a coping mechanism, letting some patients adopt positive views about their condition (Wu et al. 2015) including Muslim patients who recognise health and illness as a natural part of the life which comes from God (Yodchai et al. 2017). Psycho-spiritual interventions may be particularly relevant to aid adjustment to HD amongst Turkish-Cypriots and indeed for patients from other cultural backgrounds where religion and or spirituality offers meaning and facilitates coping (Egan et al. 2015).

The role of the family network was further emphasised as crucial to patients and concurs with the wider literature (Hoang et al. 2018). It is essential for future research to consider the impact of informal care on family members so as to explore support needs as caring for a patient receiving HD can be complex (Hoang et al. 2018).

Cognitive reframing was identified as the final coping mechanism. Patients receiving HD have been found to see this as a life-line, though with significant consequences (Jones et al. 2018). Most patients in our study attempted to adopt cognitions that helped them to first recognise the life extending nature of $\mathrm{HD}$, and second, some adopted avoiding the fact that 
they had a long-term condition and appreciating their physical status. By trying to have a positive attitude they shifted their attention from negative thoughts regarding their condition. Maintaining a positive attitude can be considered as an adaptive process to the difficulties of HD (Pelletier-Hibbert \& Sohi 2001).

\section{Limitations}

Whilst we have described the illness perceptions of a patient group currently underrepresented in research, there are some limitations to consider. Evidence suggests that analysing qualitative data in its original language is advantageous (van Nes et al. 2010), however there may be nuances that result in some loss of meaning when researchers do transliteration. That is the process of replacing words of the original language with a similar meaning in the target language when exact equivalent words do not exist (Regmi et al. 2010). Effort was made to minimise the loss of meaning by the lead researcher conducting and analysing the interviews being a native Turkish speaker with high proficiency in the English language. We also employed rigorous quality assurance measures though it is still plausible that some residual loss of semantic meaning may have occurred. Additionally, interviews were undertaken with a purposive sample. The extent to which our themes can be extrapolated beyond the study sample is therefore unclear, though we have highlighted a number of parallels with existing evidence. This likely reflects the stability of some types of illness perceptions across cultures.

\section{Implications for Practice}

Our study has demonstrated the usefulness of the illness perceptions framework when exploring the lived experiences of distinct patient groups. Identified codes and themes aligned to the domains of illness perceptions and highlighted important knowledge gaps that 
shape how patients understand and make sense of kidney failure. Illness perceptions are amenable to change (Petrie et al. 2002) and evidence for interventions is promising (Sararoudi et al. 2016). For Turkish Cypriots receiving HD, key intervention components will need to address illness identity and cause and draw on psycho-spiritual coping to enhance cultural relevance. Orientation towards spiritual coping may have broader applicability for health care professionals caring for patients from the same or similar cultural backgrounds who are receiving HD in different regions. Campaigns targeting patient acceptance of living donation may also be advantageous to bolster cure/control beliefs.

\section{Conclusion}

This study highlights how Turkish Cypriot patients receiving HD experience their illness physically, psychologically, and emotionally. Importantly, it also unearths coping mechanisms that facilitate adjustment to a new sense of self. Interventions that help patients understand their condition better and that advance culturally tailored adjustment may be useful to encourage better outcomes. 


\section{References}

Azar M., Kroll T., \& Bradbury-Jones C. (2016). Lebanese women and sexuality: A qualitative inquiry. Sexual \& Reproductive Healthcare, 8, 13-18. https://doi.org/10.1016/j.srhc.2016.01.001

Bonsaksen T., Lerdal, A. \& Fagermoen M.S. (2015). Trajectories of illness perceptions in persons with chronic illness: An explorative longitudinal study. Journal of Health Psychology, 20(7), 942-953. https://doi.org/10.1177/1359105313504235

Braun V. \& Clarke V. (2006). Using thematic analysis in psychology. Qualitative Research in Psychology, 3(2), 77-101. https://doi.org/10.1191/1478088706qp063oa

Braun V. \& Clarke V. (2013). Successful Qualitative Research. London: Sage

Broadbent E., Petrie K.J., Main, J. et al. (2006). The Brief Illness Perception Questionnaire. Journal of Psychosomatic Research, 60(6), 631-637.

https://doi.org/10.1016/j.jpsychores.2005.10.020

Bujang M.A., Musa R., Liu W.J. et al. (2015). Depression, anxiety and stress among patients with dialysis and the association with quality of life. Asian Journal of Psychiatry, 18, 49-52. https://doi.org/10.1016/j.ajp.2015.10.004

Chilcot J. (2012). The importance of illness perception in end-stage renal disease: associations with psychosocial and clinical outcomes. In Seminars in dialysis (Vol. 25, No. 1, pp. 59-64). Oxford, UK: Blackwell Publishing Ltd.

Chilcot J, Guirguis A., Friedli K. et al. (2018). Depression symptoms in haemodialysis patients predict all-cause mortality but not kidney transplantation: A cause-specific outcome analysis. Annals of Behavioral Medicine, 52(1), 1-8. 
https://doi.org/10.1007/s12160-017-9918-9

Connor T.M.F., Oygar, D.D., Gale D.P. et al. (2013). Incidence of End-Stage Renal Disease in the Turkish-Cypriot Population of Northern Cyprus: A Population Based Study. PLoS ONE, 8(1), 1-7. https://doi.org/10.1371/journal.pone.0054394

Cukor D., Peterson R.A., Cohen S.D. et al. (2006). Depression in end-stage renal disease hemodialysis patients. Nature Clinical Practice Nephrology, 2(12), 678-687. https://doi.org/10.1038/ncpneph0359

Egan R., Wood S., MacLeod R. et al. (2015, December). Spirituality in renal supportive care: A thematic review. In Healthcare (Vol. 3, No. 4, pp. 1174-1193). Multidisciplinary Digital Publishing Institute. https://doi.org/10.3390/healthcare3041174

Gerogianni G., Polikandrioti M., Babatsikou F. et al. (2019). Anxiety-Depression of Dialysis Patients and Their Caregivers. Medicina, 55(5), 168. https://doi.org/10.3390/medicina55050168

Gibbons C.J., Kenning C., Coventry P.A. et al. (2013). Development of a Multimorbidity Illness Perceptions Scale (MULTIPleS). PLoS ONE, 8(12), 1-12. https://doi.org/10.1371/journal.pone.0081852

Hagger M.S., Koch S., Chatzisarantis N.L. et al. (2017). The common sense model of selfregulation: Meta-analysis and test of a process model. Psychological Bulletin, 143(11), 1117. https://doi.org/10.1037/bul0000118

Hoang V.L., Green T. \& Bonner A. (2018). Informal caregivers' experiences of caring for people receiving dialysis: A mixed-methods systematic review. Journal of Renal Care, 44(2), 82-95. https://doi.org/10.1111/jorc.12235 
Jones D.J.W., Harvey K., Harris J.P. et al. (2018). Understanding the impact of haemodialysis on UK National Health Service patients' well-being: A qualitative investigation. Journal of Clinical Nursing, 27(1-2), 193-204. https://doi.org/10.1111/jocn.13871

Kazley A.S., Johnson E., Simpson K., et al. (2015). African American patient knowledge of kidney disease: a qualitative study of those with advanced chronic kidney disease. Chronic Illness, 11(4), 245-255 https://doi.org/10.1177/1742395314556658

Kim Y. \& Evangelista, L.S. (2010). Relationship between Illness Perceptions, Treatment Adherence, And Clinical Outcomes in Patients On Maintenance Hemodialysis. Nephrology Nursing Journal : Journal of the American Nephrology Nurses' Association, 37(3), 271-281. https://doi.org/10.1097/MCA.0000000000000178.Endothelial

Kittiskulnam P., Sheshadri A. \& Johansen K.L. (2017). Consequences of CKD on Functioning. Seminars in Nephrology, 36(4), 305-318. https://doi.org/10.1016/j.semnephrol.2016.05.007

Kizilyürek N. \& Gautier-Kizilyürek S. (2004). The politics of identity in the Turkish Cypriot community and the language question. International Journal of the Sociology of Language (168), 37-54. https://doi.org/10.1515/ijs1.2004.032

Leventhal H., Brissette I., Leventhal E. et al. (2003). The common-sense model of selfregulation of health and illness. The Self-Regulation of Health and Illness Behaviour, (January 2003), 42-65. https://doi.org/10.1093/rheumatology/kem060

Leventhal H., Phillips L.A. \& Burns E. (2016). The Common-Sense Model of SelfRegulation (CSM): a dynamic framework for understanding illness selfmanagement. Journal of Behavioral Medicine, 39(6), 935-946. 
https://doi.org/10.1007/s10865-016-9782-2

Loosman W.L., Rottier M.A., Honig A. et al. (2015). Association of depressive and anxiety symptoms with adverse events in Dutch chronic kidney disease patients: A prospective cohort study. BMC Nephrology, 16(1), 1-8. https://doi.org/10.1186/s12882-015-0149-7

Moss-Morris R., Weinman J., Petrie K. et al. (2002). The revised Illness Perception Questionnaire (IPQ-R). Psychology and Health, 17(1), 1-16. https://doi.org/10.1080/08870440290001494

Nabolsi M.M., Wardam L. \& Al-Halabi J.O. (2015). Quality of life, depression, adherence to treatment and illness perception of patients on haemodialysis. International Journal of Nursing practice, 21(1), 1-10. https://doi.org/10.1111/ijn.12205

Ng H.J., Tan W.J., Mooppil N. et al. (2015). Prevalence and patterns of depression and anxiety in hemodialysis patients: A 12-month prospective study on incident and prevalent populations. British Journal of Health Psychology, 20(2), 374-395. https://doi.org/10.1111/bjhp.12106

Ng C.Y., Lee Z.S. \& Goh K.S. (2016). Cross-sectional study on knowledge of chronic kidney disease among medical outpatient clinic patients. Medical Journal of Malaysia, 71(3), 99.

Oflaz S., Yüksel Ş., Fatma Ş.E.N. et al. (2014). Does illness perception predict posttraumatic stress disorder in patients with myocardial infarction? Nöro Psikiyatri Arşivi, 51(2)

Parfeni M., Nistor I. \& Covic A. (2013). A systematic review regarding the association of illness perception and survival among end-stage renal disease patients. Nephrology Dialysis Transplantation, 28(10), 2407-2414. https://doi.org/10.1093/ndt/gft194 
Patel S.S., Shah V.S., Peterson R.A. et al. (2002). Psychosocial variables, quality of life, and religious beliefs in ESRD patients treated with hemodialysis. American Journal of Kidney Diseases, 40(5), 1013-1022. https://doi.org/10.4274/npa.y6394

Patton M.Q. (2015). Sampling, qualitative (purposeful). The Blackwell Encyclopedia of Sociology. DOI: 10.1002/9781405165518.wbeoss012.pub2

Pelletier-Hibbert, M. \& Sohi P. (2001). Sources of uncertainty and coping strategies used by family members of individuals living with end stage renal disease. Nephrology Nursing Journal, 28(4), 411.

Peterson R.A., Kimmel P.L., Sacks C.R. et al. (1991). Depression, Perception of Illness and Mortality in Patients with End-Stage Renal Disease. The International Journal of Psychiatry in Medicine, 21(4), 343-354. https://doi.org/10.2190/D7VA-FWEU-JN5YTD3E

Petrie K.J., Cameron L.D., Ellis C.J. et al. (2002). Changing illness perceptions after myocardial infarction: an early intervention randomized controlled trial. Psychosomatic Medicine, 64(4), 580-586. https://doi.org/10.1097/00006842-200207000-00007

Petrie K.J. \& Weinman J. (2006). Why illness perceptions matter. Clinical Medicine, 6(6), 536-539. https://doi.org/10.7861/clinmedicine.6-6-536

Picariello F, Norton S., Moss-Morris R. et al. (2019). A prospective study of fatigue trajectories among in-centre haemodialysis patients. British Journal of Health Psychology. https://doi.org/10.1111/bjhp.12395

Rees J., Chilcot J., Donnellan W. et al. (2018). Exploring the nature of illness perceptions in people with end-stage kidney disease. Journal of Renal Care, 44(1), 19-29. https://doi.org/10.1111/jorc. 12225 
Regmi K., Naidoo J. \& Pilkington P. (2010). Understanding the Processes of Translation and Transliteration in Qualitative Research. International Journal of Qualitative Methods, 9, 16-26. https://doi.org/10.1177/160940691000900103

Sadagah L.F., Makeen A., Alharthi M. et al. (2020, July). Willingness of Hemodialysis Patient's Family Members Toward Kidney Donation: A Cross-Sectional Study. In Transplantation Proceedings. https://doi.org/10.1016/j.transproceed.2020.05.017

Sararoudi R.B., Motmaen M., Maracy M.R. et al. (2016). Efficacy of illness perception focused intervention on quality of life, anxiety, and depression in patients with myocardial infarction. Journal of Research in Medical Sciences: the Official Journal of Isfahan University of Medical Sciences, 21.

Seyyedrasooli A., Parvan K., Rahmani A. et al. (2013). Effect of illness perception promoting interventions on treatment adherence in hemodialysis patients: A randomized controlled trial. Iranian Journal Critical Care Nursing, 6, 2, 77-86.

Sharma S., King M., Mooney R. et al. (2019). How do patients from South Asian backgrounds experience life on haemodialysis in the UK? A multicentre qualitative study. BMJ Open, 9(5). https://doi.org/10.1136/bmjopen-2018-024739

Shirazian S., Grant C.D., Aina O. et al. (2017). Depression in Chronic Kidney Disease and End-Stage Renal Disease: Similarities and Differences in Diagnosis, Epidemiology, and Management. Kidney International Reports, 2(1), 94-107. https://doi.org/10.1016/j.ekir.2016.09.005

Stel V.S., van de Luijtgaarden M.W.M., Wanner C. et al. (2011). The 2008 ERA-EDTA Registry Annual Report. Nephrology Dialysis Transplantation Plus, 4(1), 1-13. https://doi.org/10.1093/ndtplus/sfq191 
Temple B. \& Young A. (2004). Qualitative research and translation dilemmas. SAGE Publications (Vol. 4). https://doi.org/10.1177/1468794108095079

Tong A., Sainsbury P. \& Craig J. (2007). Consolidated criteria for reporting qualitative research (COREQ): a 32 - item checklist for interviews and focus groups. International Journal for Quality in Health Care 19, 349-357. https://doi.org/10.1093/intqhe/mzm042

Tong A., Sainsbury P., Chadban S. et al. (2009). Patients' Experiences and Perspectives of Living With CKD. American Journal of Kidney Diseases, 53(2), 689-700. https://doi.org/10.1053/j.ajkd.2008.10.050

Tong A., Winkelmayer W.C. \& Craig J.C. (2014). Qualitative research in CKD: An overview of methods and applications. American Journal of Kidney Diseases, 64(3), 338-346. https://doi.org/10.1053/j.ajkd.2014.02.026

van Nes F., Abma T., Jonsson H. et al. (2010). Language differences in qualitative research: Is meaning lost in translation? European Journal of Ageing, 7(4), 313-316. https://doi.org/10.1007/s10433-010-0168-y

Vandermause R., Barg F.K., Esmail L. et al. (2017). Qualitative methods in patient-centered outcomes research. Qualitative Health Research, 27(3), 434-442. https://doi.org/10.1177/1049732316668298

Wu C.C., Lin C.C., Hsieh H.F. et al. (2015). Lived experiences and illness representation of Taiwanese patients with late-stage chronic kidney disease. Journal of Health Psychology, 21(12), 2788-2798. https://doi.org/10.1177/1359105315587134

Yeoh S.H., Tam C.L., Wong C.P. et al. (2017). Examining depressive symptoms and their predictors in Malaysia: Stress, locus of control, and occupation. Frontiers in Psychology, 8(AUG), 1-10. https://doi.org/10.3389/fpsyg.2017.01411 
Yildirim N.K., Okanli A., Karabulutlu E.Y. et al. (2013). Effects of illness perception on anxiety and depressive symptoms in hemodialysis patients: a multi-center study. Anadolu Psikiyatri Dergisi-Anatolian Journal of Psychiatry, 14(3), 252-259. https://doi.org/10.5455/apd.40629

Yodchai K., Dunning T., Savage S. et al. (2017). The role of religion and spirituality in coping with kidney disease and haemodialysis in Thailand. Scandinavian Journal of Caring Sciences, 31(2), 359-367. https://doi.org/10.1111/scs.12355 
Table 1. Demographic and clinical characteristics of the participants.

\begin{tabular}{|c|c|c|c|c|c|}
\hline \multirow[t]{2}{*}{ Participants } & \multirow[t]{2}{*}{ Gender } & \multirow[t]{2}{*}{ Age } & \multicolumn{2}{|c|}{ Dialysis vintage } & \multirow[t]{2}{*}{ Comorbidity status } \\
\hline & & & $\mathrm{PD}$ & HD & \\
\hline P1 & $\mathrm{M}$ & 76 & $5 \mathrm{y}$. & $8 \mathrm{y}$. & Ischemic heart disease \\
\hline $\mathrm{P} 2$ & $\mathrm{~F}$ & 64 & - & $1 \mathrm{y}$. & Ischemic heart disease \\
\hline P3 & $\mathrm{F}$ & 77 & - & $4.5 \mathrm{y}$ & Hypertension \\
\hline P4 & M & 81 & - & $7 \mathrm{y}$. & Hypertension \& Lymphoma \\
\hline P5 & M & 77 & - & $12 \mathrm{y}$. & $\begin{array}{l}\text { Ischemic heart disease \& Hypertension \& } \\
\text { Peripheral vascular disease }\end{array}$ \\
\hline P6 & $\mathrm{F}$ & 61 & - & $7 \mathrm{y}$. & Hypertension \& Thyroid disease \\
\hline P7 & $\mathrm{F}$ & 48 & - & $2 \mathrm{y}$. & Diabetes \& Hypertension \& Amputee \\
\hline P8 & M & 75 & - & $6 \mathrm{~m}$. & Hypertension \& Rheumatism \\
\hline P9 & M & 76 & - & $2 \mathrm{y}$ & $\begin{array}{l}\text { Hypertension \& Diabetes \& Ischemic heart } \\
\text { disease }\end{array}$ \\
\hline P10 & M & 79 & - & $3 \mathrm{y}$. & Hypertension \\
\hline $\mathrm{P} 11^{*}$ & $\mathrm{M}$ & 58 & $8.5 \mathrm{y}$. & $6 \mathrm{y}$. & Hepatitis C \\
\hline $\mathrm{P} 12$ & M & 82 & - & $8 \mathrm{~m}$. & Hypertension \\
\hline $\mathrm{P} 13$ & $\mathrm{~F}$ & 78 & - & $2 \mathrm{y}$. & Diabetes \& Cervical cancer \\
\hline P14 & $\mathrm{F}$ & 48 & - & $2 \mathrm{y}$. & Hypertension \\
\hline
\end{tabular}

*had kidney transplantation (7.5 y.). y: years; m: months. 
Table 2. Summary of thematic analysis

\begin{tabular}{cl}
\hline Themes & \multicolumn{1}{c}{ Subthemes } \\
\hline 1. Illness appraisal & 1.1 Sense making \\
& 1.2 Causal beliefs \\
& 1.3 Expectations for the future \\
2. Life changing effects & 2.1 Physical \\
& 2.2 Emotional and cognitive \\
& 2.3 Social restrictions \\
& 2.4 Normalising HD \\
3. Active coping strategies & 3.1 Religious /spiritual attitudes \\
& 3.2 Social Support \\
& 3.3 Cognitive reframing \\
\hline
\end{tabular}

